\title{
El derecho a la protección de datos personales y el reconocimiento de la autodeterminación informativa en la Constitución chilena
}

\author{
The right to the protection of personal data and the recognition \\ of informational self-determination in the Chilean Constitution
}

\author{
Pablo CONTRERAS ${ }^{1}$ \\ Universidad Autónoma de Chile \\ pablo.contreras@uautonoma.cl
}

\begin{abstract}
Resumen: El texto examina el reconocimiento del derecho a la protección de datos personales como un derecho fundamental en la Constitución chilena. Para ello revisa la historia legislativa de la reforma constitucional y los principales debates que se produjeron. En particular, se revisan tres dilemas: primero, la necesidad de constitucionalizar o no la autodeterminación informativa como derecho fundamental; segundo, la densidad normativa requerida para constitucionalizar el derecho; y la relación de titularidad o propiedad sobre los datos personales. El texto
\end{abstract}

1 Doctor en Derecho (SJD), Northwestern University. Profesor de Derecho Constitucional y Director del Centro de Regulación y Consumo de la Universidad Autónoma de Chile.

Este trabajo es parte de la investigación financiada por Fondecyt de Iniciación de la Comisión Nacional de Investigación Científica y Tecnológica, bajo el No. 11180218, con el título: "El reconocimiento y protección de la autodeterminación informativa como marco teórico adecuado para la comprensión de los derechos de las personas en tanto límite al acceso a la información pública”.

Quisiera agradecer los comentarios de Michelle Bordachar, Ana Muñoz, Pablo Viollier, Pablo Trigo y de todos los participantes del Workshop de Artículos Científicos de Investigadores del Instituto de Investigación en Derecho de la Universidad Autónoma de Chile. Los defectos subsistentes son de exclusiva responsabilidad del autor.

Artículo recibido el 23.09.2019 y aceptado para publicación el 27.05.2020. 
concluye anticipando dos desafíos para la regulación del derecho: primero, relativo al tipo de remisión o reserva al legislador del mandato de protección de datos personales y, segundo, a la garantía de la autodeterminación informativa y, en particular, a la protección del derecho a través del recurso de protección, a través del habeas data y a través de una agencia especializada como autoridad de control.

Palabras claves: Datos personales, Autodeterminación informativa, Derecho a la protección de datos personales

\begin{abstract}
The paper examines the recognition of the right to the protection of personal data as a fundamental right in the Chilean Constitution. To this end, it reviews the legislative history of the constitutional amendment and the main debates that took place. In particular, three dilemmas are reviewed: first, the need to constitutionalize or not informational self-determination as a fundamental right; second, the normative density required to constitutionalize the right; and, third, the legal relationship of entitlement or ownership over personal data. The text concludes by anticipating two challenges for the legal regulation of the right: first, regarding the type of constitutional referral to the legislator to protect personal data and, second, the jurisdictional protection of informational self-determination and, in particular, the protection of the right through the recurso de protección, through habeas data and through a specialized agency as control authority.
\end{abstract}

Keywords: Personal data, Informational self-determination, Right to the protection of personal data

\title{
1. Introducción
}

No es usual que se agregue un derecho fundamental en la Constitución de un país. En el caso de Chile, es sumamente excepcional y sólo ha ocurrido en dos oportunidades. La primera vez fue el reconocimiento de la libertad de creación artística, en el artículo 19 No. 25 de la Constitución ${ }^{2}$. La segunda, fue en el año 2018, cuando se consagró explícitamente el derecho a la protección de datos personales, también conocido como autodeterminación informativa, incorporado por una reforma constitucional a través de la Ley No. 21.096, que modificó el

2 Ley No. 19.742, Reforma constitucional que elimina la censura cinematográfica sustituyéndola por un sistema de calificación y que consagra el derecho a la libre creación artística. Diario Oficial, 25 de agosto de 2001. 
artículo 19 No. 4 de la Constitución ${ }^{3}$. Este artículo aborda la creación del nuevo derecho a la protección de datos personales.

Antes de este reconocimiento expreso, el derecho a la protección de datos personales se había entendido como parte del contenido iusfundamentalmente protegido del derecho al respeto y protección de la vida privada, establecido en el artículo $19 \mathrm{~N}^{\circ} 4$ de la Constitución. Así lo había argumentado la doctrina ${ }^{4}$ y la jurisprudencia mayoritaria 5 . Pero hoy eso debe ser repensado a partir del reconocimiento explícito del derecho a la autodeterminación informativa como un derecho independiente del derecho a la vida privada, consagrado a partir de la reforma constitucional del 2018.

¿Cuáles fueron los antecedentes que los colegisladores tuvieron a la vista? ¿Cuáles fueron los principales dilemas que el reconocimiento del derecho tuvo que sortear? ¿Cuáles son algunos de los desafíos que ahora deberá enfrentar el legislador, de cara a una futura reforma de la Ley No. 19.628, sobre protección de la vida privada? Este texto tiene por objeto dar cuenta de estas preguntas, en torno a la creación del derecho a la protección de datos personales. Para ello, analiza como fuente primaria la historia de la reforma y los debates que surgieron a efectos de su reconocimiento constitucional (en adelante, "HDL") 6 . Adicionalmente, recurre a las fuentes doctrinales y jurisprudenciales, tanto nacionales como comparadas, que permiten ilustrar estos debates. Esta revisión, sin embargo, es acotada y funcional a la lectura e interpretación de los alcances constitucionales bajo los cuales se buscó configurar la autodeterminación informativa y no tiene por finalidad un trabajo dogmático respecto de la estructura de este o sus presupuestos. En otros términos, este trabajo no tiene por objeto analizar el derecho en sí sino revisar cómo se llegó a su constitucionalización expresa y cuáles fueron los acuerdos y cuestiones postergadas tras el debate constitucional. Queda pendiente, entonces,

\footnotetext{
3 Si bien sólo dos derechos se han incorporado a la Constitución de 1980, vía reforma constitucional, cabe precisar que sí se han integrado atributos o propiedades de otros derechos a través de enmiendas constitucionales. Véase, por ejemplo, la Ley 19.876, Reforma constitucional que establece la obligatoriedad y gratuidad de la educación media, o la Ley No. 20.710, Reforma constitucional que establece la obligatoriedad del segundo nivel de transición y crea un sistema de financiamiento gratuito desde el nivel medio menor.

4 Banda (2000); Nogueira (2005).

5 Tribunal Constitucional, Roles $\mathrm{N}^{\circ}$ 1732-10 y 1800-10, de 21 de junio de 2011; FigueroA (2014).

6 En adelante, citaré el documento de la Biblioteca del Congreso Nacional que compila el trámite legislativo de la reforma constitucional como "HDL". Para su revisión, puede consultarse Biblioteca DEL Congreso Nacional (2018), Historia de la Ley No. 21.096 Consagra el Derecho a Protección de Datos Personales. [Fecha de consulta: 24.04.19] [Disponible en: https://www.bcn.cl/historiadelaley/fileadmin/file_ley/7551/HLD_7551_37a6259ccoc1dae299a7866489dffobd.pdf].
} 
para futuras investigaciones, la descripción y análisis de aspectos doctrinales del derecho mismo, tales como la regla de titularidad del derecho, sus destinatarios, el objeto de protección o sus límites -por mencionar algunos de sus presupuestos-, y sin perjuicio de que algunas de estas materias ya se avanzan en las páginas que siguen.

El trabajo se estructura de la siguiente forma. En primer lugar, se revisan los antecedentes de la reforma constitucional, en donde se caracteriza la moción que le dio origen y sus antecedentes comparados y nacionales. En segundo término, se examinan los principales dilemas de la discusión legislativa que influyeron en el reconocimiento y alcance del derecho a la protección de datos personales. En particular, se revisan tres dilemas: la necesidad de constitucionalizar o no la autodeterminación informativa como derecho fundamental; la densidad normativa necesaria al momento de constitucionalizar el derecho; y la relación de titularidad o propiedad sobre los datos personales. El texto concluye anticipando dos desafíos para la regulación del derecho: primero, relativo al tipo de remisión o reserva al legislador del mandato de protección de datos personales y, segundo, a la garantía de la autodeterminación informativa y, en particular, a la protección del derecho a través del recurso de protección, a través del habeas data y a través de una agencia especializada como autoridad de control.

\section{Antecedentes de la reforma constitucional}

La reforma constitucional que consagró el derecho a la protección de datos personales en la Constitución, tiene su origen en una moción del año 2014, liderada por el senador Harboe y suscrita por los senadores Araya y Lagos y los ex senadores Larraín y Tuma. En sus fundamentos, la moción destaca los antecedentes comparados respecto de la protección de datos personales y la inexistente garantía de este derecho en nuestro país?

\subsection{El objeto de la reforma constitucional}

La inclusión del derecho a la protección de datos personales, de forma autónoma al derecho al respeto y protección de la vida privada, es una de las cuestiones que los debates legislativos buscaron esclarecer. La moción fundamenta la autonomía

7 HDL, p. 3. 
del derecho a la protección de datos citando especialmente dos de las principales sentencias constitucionales sobre esta materia en el derecho comparado ${ }^{8}$ : el caso del Censo fallado por el Tribunal Constitucional Federal Alemán ${ }^{9}$ y la sentencia del Tribunal Constitucional español sobre el alcance del derecho a la protección de datos personales en la Constitución de $1978^{10}$.

La moción recalca principalmente el análisis del Tribunal Constitucional español. Conforme a éste, la protección de datos personales es un derecho distinto de la intimidad, tanto en su función como en su objeto y contenido ${ }^{11}$. En materia de función, mientras que la intimidad protege frente invasiones al "ámbito de la vida personal y familiar que la persona desea excluir del conocimiento ajeno y de las intromisiones de terceros en contra de su voluntad", la protección de datos personales tiene por función garantizar a su titular "un poder de control sobre sus datos personales, sobre su uso y destino, con el propósito de impedir su tráfico ilícito y lesivo para la dignidad y derecho del afectado"12. Por ello, el objetivo del derecho a la protección de datos personales es más amplio que el de la intimidad. En los términos del Tribunal Constitucional español, "el objeto de protección del derecho fundamental a la protección de datos no se reduce sólo a los datos íntimos de la persona, sino a cualquier tipo de dato personal, sea o no íntimo, cuyo conocimiento o empleo por terceros pueda afectar a sus derechos, sean o no fundamentales, porque su objeto no es sólo la intimidad individual, [...] sino los datos de carácter personal"13.

Sin embargo, la moción opta por una inclusión en el mismo artículo 19 No. 4 que asegura el respeto y protección de la vida privada. Textualmente, señala que a pesar del carácter autónomo de la autodeterminación informativa, como derecho fundamental, "la presente reforma propone su regulación en el artículo $19 \mathrm{n}^{\circ} 4 \mathrm{de}$ la CPR, ya que reconoce que se trata de un derecho derivado de la intimidad, y es en ese entendido, la razón de su ubicación"14.

8 HDL, pp. 3-4.

9 Si bien la moción cita el caso de 1983 -Sentencia del Tribunal Constitucional Federal Alemán, BVerfGE 65, 1 (1983)-, ya en 1969 la cuestión fue debatida a partir del caso "Microcenso", sentencia del Tribunal Constitucional Federal Alemán, BVerfGE 27, 1 (1969). Para sus versiones traducidas, véase a ScHwabe (2009).

10 Sentencia del Tribunal Constitucional Español ("STCE") 292/2000.

11 STCE 292/2000, fj. 5.

12 STCE 292/2000, fj. 6.

13 STCE 292/2000, fj. 7.

14 HDL, pp. 4-5. 
El proyecto de ley original proponía incorporar dos incisos nuevos en el artículo 19 No. 4 de la Constitución. El primer inciso establecía lo siguiente: “[t]oda persona tiene derecho a la protección de sus datos personales y obtener su rectificación, complementación”. El segundo, proponía lo siguiente: “[s]u tratamiento sólo podrá hacerse por ley o con el consentimiento expreso del titular".

\subsection{Antecedentes comparados}

Desde el punto de vista comparado, la constitucionalización del derecho a la autodeterminación informativa estuvo siempre motivada por compromisos internacionales y por los estándares internacionales que a la fecha se habían consolidado. Así, por ejemplo, una referencia constante fue el compromiso del Estado frente a la Organización para la Cooperación y el Desarrollo Económicos (“OCDE”), en torno a la necesidad de actualizar la regulación y protección de los datos personales en el país ${ }^{15}$. La moción destacaba la necesidad de ajustar la regulación chilena a las "Recomendaciones" de la OCDE de 1980". A lo largo de la tramitación legislativa y, especialmente en los debates en sala, los parlamentarios insistirán en la necesidad de cumplir con el compromiso de la OCDE. En particular, Chile aceptó "los instrumentos antes mencionados [relativos a la protección de datos personales] con un plazo para su implementación hasta fines de 2011" ${ }^{17}$. A la fecha, sin embargo, el compromiso se mantiene pendiente ${ }^{18}$.

Otros antecedentes que tuvieron menor atención fueron las referencias al Consejo de Europa y a la Unión Europea. En este sentido, el Convenio para la protección de las personas con respecto al tratamiento automatizado de datos de carácter personal (en adelante, "Convenio No. 108") 19, fue invocado como parte de los fundamentos de la moción pero su contenido no tuvo mayor desarrollo en las discusiones sobre la reforma ${ }^{20}$. Cabe destacar que el Convenio No. 108 es el primer tratado internacional relativo a la protección de datos personales. Fue

15 OCDE (2009), p. 22 (traducción propia).

$16 \mathrm{HDL}, \mathrm{p}$. 3. Si bien la moción se refiere a "Recomendaciones", debiésemos entender que la referencia se efectúa a las "Directrices sobre protección de la privacidad y flujos transfronterizos de datos personales". Véase OCDE (1980).

17 HDL, pp. 22, 51, 53, 58, 62, 102, 108, 113, 123, 130 y 131.

$18 \mathrm{Al}$ respecto, véase CÁmara de Diputados (2016), p. 67.

19 Convenio No. 108, para la protección de las personas con respecto al tratamiento automatizado de datos de carácter personal. [Fecha de consulta: 09.08.19] [Disponible en: https://rm.coe.int/168o6c1abd].

20 HDL, pp. 3, 7, 13, 22, 58 y 91. 
adoptado en 1981 y entró en vigencia en 1985 y tiene la particularidad de ser un tratado abierto a la firma por cualquier Estado y no sólo los miembros del Consejo de Europa. Actualmente, tiene 54 Estados parte y Argentina fue el último Estado de Latinoamérica en ratificarlo, junto a Uruguay y México ${ }^{21}$. Por otra parte, en relación a la Unión Europea, la moción invocaba la Directiva 95/46/CE del Parlamento Europeo y del Consejo de la Unión Europea, relativa a la protección de las personas físicas en lo que respecta al tratamiento de datos personales y a la libre circulación de estos datos, adoptada en el año 1995 (en adelante, "Directiva 95/46") ${ }^{22}$. Una de las cuestiones centrales de los referentes europeos fue la centralidad de la persona como sujeto de protección al tener que regularse los datos personales. En particular, a partir de la normativa europea se busca orientar la reforma constitucional en términos tales que el tratamiento de datos personales esté "al servicio del hombre" y que respeten "las libertades y derechos fundamentales de las personas físicas y, en particular, la intimidad, y contribuir al progreso económico y social, al desarrollo de los intercambios, así como al bienestar de los individuos" ${ }^{23}$. Esta fundamentación -aun cuando la moción no lo señalara- empalmaba correctamente con las bases de la institucionalidad de la Constitución, en los que se establece el principio de servicialidad del Estado, respecto de la persona, y se establece como finalidad del mismo el bien común, prohibiendo la instrumentalización de los individuos para alcanzar fines colectivos ${ }^{24}$ (art. 1, inc. $4^{\circ}$ de la Constitución).

\subsection{Antecedentes nacionales}

Desde el punto de vista de los antecedentes nacionales, se tuvieron a la vista tanto ciertos aportes de la literatura constitucional como algunos desarrollos jurisprudenciales. Dos trabajos fueron especialmente citados a efectos de configurar el derecho en cuestión. En primer lugar, el texto del profesor Enrique Rajevic ${ }^{25}$

21 La tabla de firmas y ratificaciones se encuentra disponible [en línea]: https://www.coe.int/en/web/conventions/full-list/-/conventions/treaty/108/signatures?p_auth=SWNsnUpq [Fecha de consulta: 09.7.19].

22 Directiva 95/46/CE del Parlamento Europeo y del Consejo, de 24 de octubre de 1995, relativa a la protección de las personas físicas en lo que respecta al tratamiento de datos personales y a la libre circulación de estos datos. [Fecha de consulta: 09.7.19]. [Disponible en: https://eur-lex.europa.eu/legal-content/ES/ TXT/?uri=celex\%3A31995Loo46].

23 HDL, p. 3. Véase también HDL, pp. 13, 22, 52 y 59.

24 García et al. (2016), p. 103; Nogueira (2012), p. 577.

25 RAJEVIC (2011). 
fue invocado para explicar dos dimensiones del derecho a la protección de datos personales. La faz negativa, en sentido de no interferencia y como una barrera de protección frente a injerencias ilegítimas en el ejercicio del derecho a la privacidad y la faz positiva, como un derecho de autodeterminación informativa, esto es, como un derecho "de las personas a controlar sus datos personales, incluso si éstos no se refieren a su intimidad" ${ }^{26}$. Este aspecto conceptual era relevante para poder deslindar el carácter autónomo del derecho a la protección de datos personales frente al derecho a la protección de la vida privada o la intimidad. En segundo lugar, el trabajo del profesor Humberto Nogueira sobre habeas data fue recurrentemente citado durante la tramitación de la reforma ${ }^{27}$. La contribución de Nogueira será central para configurar el contenido del derecho. A partir de una revisión de las fuentes primarias y secundarias sobre la autodeterminación informativa y el habeas data, es posible entender que los legisladores entendían que el derecho que estaban constitucionalizando, comprendía una facultad de acceso, complementación o rectificación de los datos personales de un titular, frente al sujeto de naturaleza pública o privada, responsable del tratamiento en cuestión ${ }^{28}$. Esta referencia ya a nivel de la moción, pero reiterada a lo largo de la tramitación de la reforma, nos da cuenta de una intención de constitucionalizar las facultades conocidas como derechos "ARCO”, esto es, los derechos de acceso, rectificación, cancelación y oposición, recogidas ampliamente en la doctrina nacional ${ }^{29}$.

Otro antecedente nacional fue la interpretación del Tribunal Constitucional que estimó que el derecho a la protección de datos personales se encuentra recogido a partir del art. 19 No. 4, que establece el derecho al respeto y protección de la vida privada ${ }^{30}$. La sentencia se enmarca en un caso en que se cuestionaba la inaplicabilidad por inconstitucionalidad del precepto legal del artículo décimo, letra h) de la Ley no. 20.285, sobre acceso a la información pública, que dispone la obligación de transparencia activa de "remuneración percibida en el año por cada Director, Presidente Ejecutivo o Vicepresidente Ejecutivo y Gerentes responsables de la dirección y administración superior de la empresa". Para los requirentes de

26 HDL, pp. 3 y 51. La cita original proviene de RAJEvic (2011), pp. 142-3.

27 Nogueira (2005). HDL, pp. 3, 7, 23, 51, 58, 62, 67 y 91.

28 HDL, pp. 3, 7, 23, 51, 58, 62, 67 y 91.

29 Jijena (1992), pp. 46-7; Vial Claro (2001), pp. 30-2; Corral (2001), pp. 42-6; Jervis (2003); Cerda (2003), pp. 52-3; Anguita (2007), pp. 304-12; Donoso (2009), pp. 72-3; De la Serna Bilbao (2011), pp. 67-8; Velásquez \& Donoso (2013), pp. 179-8o; SAlas (2014), pp. 138-42; Reusser (2018), pp. 94-8.

30 Tribunal Constitucional, Roles $\mathrm{N}^{\circ} 1732-10$ y 1800-10, de 21 de junio de 2011. 
inaplicabilidad, la publicidad de dicha información suponía una divulgación de información confidencial, en directa infracción del derecho a la privacidad del art. 19 No. 4 de la Constitución ${ }^{31}$. En dicha oportunidad, el Tribunal Constitucional interpretó lo siguiente: "la protección de la vida privada de las personas guarda una estrecha relación con la protección de los datos personales, configurando lo que la doctrina llama derecho a la autodeterminación informativa. [...] Ello se traduce en el control de las personas sobre sus datos y comprende el derecho a saber sobre la existencia de ficheros o archivos de registro de información de carácter personal, públicos o privados, cuáles son sus finalidades y quiénes son los responsables de los mismos, de manera que las personas concernidas puedan conocer los datos propios contenidos en dichos archivos o ficheros, teniendo el derecho a actualizarlos o a solicitar mediante el recurso de habeas data su rectificación o cancelación" ${ }^{32}$. La interpretación del Tribunal permitió anclar la autodeterminación informativa al contenido iusfundamentalmente protegido del derecho al respeto y protección de la vida privada. En los términos de Quezada -también citado en los fundamentos de la moción ${ }^{33}$ - “[1]a 'estrecha relación” entre vida privada y datos personales no es más que una relación de pertenencia: la protección de los segundos se ancla constitucionalmente en la protección de la primera" ${ }^{34}$. En el caso en particular, y pese al reconocimiento del derecho a la autodeterminación informativa, el Tribunal Constitucional decidió hacer prevalecer sobre éste el interés público de la divulgación de las remuneraciones de los altos funcionarios del canal estatal ${ }^{35}$.

\subsection{El antecedente ausente}

Finalmente, y para cerrar este apartado, hay que destacar que, durante la tramitación, el gran ausente fue el Reglamento 2016/679 del Parlamento Europeo y del Consejo de la Unión Europea, relativo a la protección de las personas físicas en lo que respecta al tratamiento de datos personales y a la libre circulación de estos datos (en adelante, el "Reglamento" o "RGPD")36. El Reglamento fue adoptado en

31 Sobre el caso, en general, véase CAStro \& MuÑoz (2012) y VIAL (2012).

32 Tribunal Constitucional, Roles $\mathrm{N}^{\circ} 1732-10$ y $1800-10$, de 21 de junio de 2011, cons. $25^{\circ}$.

33 HDL, p. 4.

34 QUeZada (2012), p. 139.

35 Zambrano (2018), p. 135.

36 Reglamento 2016/679 del Parlamento Europeo y del Consejo de la Unión Europea, relativo a la protección de las personas físicas en lo que respecta al tratamiento de datos personales y a la libre circulación 
abril de 2016 y entró en vigencia el 25 de mayo de 2018, derogando la Directiva 95/46. Si bien es cierto que la omisión no puede ser imputada a los creadores de la moción -toda vez que el Reglamento no existía en 2014-, durante todo el segundo trámite, el legislador podría haber atendido este nuevo estándar europeo.

Las referencias en la discusión legislativa fueron extremadamente escasas y circunstanciales. En particular, el RGPD fue citado por tres personas: la consejera del Consejo para la Transparencia, Gloria de la Fuente y los senadores Guillier y Lagos Weber. En segundo trámite ante la Cámara de Diputados, la consejera De la Fuente citó al Reglamento como parte de la nueva arquitectura normativa europea en materia de protección de datos personales ${ }^{37}$ y en relación a los estándares de independencia aplicables a las autoridades de control en esta materia ${ }^{38}$. En tercer trámite, el senador Guillier hizo presente que el RGPD es un nuevo estándar necesario de atender de cara a los flujos transfronterizos de datos personales, en particular, bajo una legislación adecuada a estándares homologables con los fijados por la Unión Europea ${ }^{39}$. Finalmente, el senador Lagos Weber citó el Reglamento para hacer presente la necesidad de contar con una legislación que establezca un duro régimen de infracciones y sanciones por "el mal uso de los datos personales" y la necesidad de contar con un "órgano independiente que vela por el cumplimiento de la normativa pertinente" 40 . La influencia del RGPD en esta reforma no fue significativa pero sin dudas será un aspecto que deberá ser atendido y estudiado en la tramitación actual del proyecto de ley que busca reformar la Ley No. $19.628^{41}$.

\footnotetext{
de estos datos. [Fecha de consulta: 08.08.19]. [Disponible en: https://eur-lex.europa.eu/legal-content/ES/ TXT/?uri=CELEX\%3A32016Ro679].

37 HDL, p. 91.

38 HDL, p. 95.

39 HDL, p. 131.

40 HDL, p. 132.

41 Revísese la tramitación conjunta del proyecto de ley que regula la protección y el tratamiento de los datos personales y crea la Agencia de Protección de Datos Personales (Boletín N $\mathrm{N}^{\circ} 11.144-07$, refundido con el Boletín $\mathrm{N}^{\circ}$ 11.092-07) y el proyecto de ley sobre protección de datos personales (Boletín $\mathrm{N}^{\circ}$ 11.092-07). [Fecha de consulta: 25.03.19] [Disponible en: https://www.camara.cl/pley/pley_detalle. aspx?prmID=11661\&prmBoletin=11144-07].
} 


\section{Agregando un nuevo derecho: los dilemas de la reforma constitucional}

Una vez analizados los antecedentes que influenciaron la constitucionalización de la autodeterminación informativa, es necesario revisar los principales dilemas conceptuales y normativos que enfrentó la reforma en su tramitación. El análisis de la discusión se centrará en tres aspectos: la necesidad de constitucionalizar o no la autodeterminación informativa como derecho fundamental; la densidad normativa necesaria al momento de constitucionalizar el derecho; y la relación de titularidad o propiedad sobre los datos personales. Esta sección tiene por objeto, en consecuencia, aportar a la configuración constitucional del derecho a la autodeterminación informativa -su reconocimiento, objeto y titularidad-a partir de los mismos debates que se dieron en el marco de la reforma constitucional.

\section{1. ¿Música celestial? La necesidad de constitucionalizar la autodeterminación informativa}

"[A] mi juicio este proyecto es más bien música celestial, ya que no va a lo esencial de esta reforma, que es proteger de verdad, en los hechos y en el derecho, los datos personales"42. Con esa afirmación, el diputado Celis sentenció duramente la reforma constitucional en su segundo trámite. De acuerdo a su opinión vertida en la Sala de la Cámara, la reforma "no protege para nada los datos personales"43. Si bien fue una opinión minoritaria, se trata de una posición que cuestionó el fondo de la necesidad y utilidad de la reforma constitucional. En esta línea, el diputado Carlos Kuschel sostuvo que la reforma era innecesaria, puesto que le parecía "que este valor está suficientemente cubierto en el número $4^{\circ}$ del artículo 19 de nuestra Constitución Política"44. Si bien ni Celis ni Kuschel detallaban por qué el proyecto era "música celestial" o redundante, a la luz del contenido protegido del art. 19 No. 4, el fondo de la crítica de Celis estaba dirigida a la necesidad de regular esta materia a través de un proyecto de ley integral ${ }^{45}$. En este sentido, se podría inferir que, al menos para el diputado Celis, la nueva norma constitucional no cambiaría el estado actual de desprotección de datos personales.

42 HDL, p. 117, énfasis agregado.

43 HDL, p. 117.

44 HDL, p. 118.

45 HDL, p. 117. 
El cuestionamiento es relevante a efectos de abordar un primer elemento de la configuración de la autodeterminación informativa: el reconocimiento positivo en la Constitución. Tal como se revisó en la sección anterior, la jurisprudencia constitucional entendía que la autodeterminación informativa era un derecho fundamental que ya se encontraba protegido por el art. 19 No. 4. Entonces, ¿por qué es necesario la constitucionalización? $\mathrm{O}$, en otros términos, ¿por qué había que hacer el derecho "explícito"?

Una primera respuesta puede ser de carácter pragmático: la reforma constitucional brinda un "paragua" ${ }^{46}$ para una futura reforma a la Ley No. 19.628 y presiona a favor de su urgencia. Esta tesis fue explícitamente defendida por uno de los creadores del proyecto, el senador Harboe, quien sostuvo que la reforma constitucional "servirá de 'paraguas' para el proyecto de ley que regula la protección y el tratamiento de datos personales y crea la Agencia de Protección de Datos Personales (boletín 11.144-07), que consagra los derechos de acceso, rectificación, cancelación, oposición y portabilidad"47. El argumento fue recogido por otros parlamentarios, como el diputado Berger ${ }^{48}$, el diputado Bianchi ${ }^{49}$ y el senador Pérez ${ }^{50}$, todos quienes enfatizaron la necesidad que el legislador desarrolle los mecanismos de protección del derecho que se estaba constitucionalizando. La diputada Hertz calificó la reforma como "una señal interesante e importante" en términos de reforzar el derecho a la privacidad y a la necesidad de actualizar la legislación actual en la materia ${ }^{51}$. Durante los diversos trámites legislativos, tanto representantes del Ejecutivo como los parlamentarios se refirieron a los proyectos de ley que tienen por objeto reformar la Ley No. 19.628, destacando tanto la compatibilidad de la constitucionalización del derecho con la futura reforma legal y la necesidad de seguir avanzando en ésta ${ }^{52}$.

Una segunda respuesta es técnicamente más relevante: constitucionalizar el derecho a la autodeterminación informativa era necesaria para delimitar conceptual y normativamente a este frente al derecho al respeto y protección de la vida privada. Primero, porque se buscaba explicitar lo implícito en el reconocimiento que

46 HDL, pp. 6o, 68, 71 y 123.

47 HDL, p. 60.

48 HDL, p. 68.

49 HDL, p. 71.

50 HDL, p. 123.

51 HDL, p. 70.

$52 \mathrm{HDL}$, pp. 10, 49, 60, 81 y 91, entre otras. 
había efectuado el Tribunal Constitucional ${ }^{53}$. Pero, segundo, porque al tratarse de un derecho "autónomo", no puede ser confundido con el contenido protegido del derecho a la privacidad. La moción cita $^{54}$, al efecto, la jurisprudencia del Tribunal Constitucional español, puesto que, según éste, la autodeterminación informativa se distingue de la privacidad e intimidad en cuanto el primero "atribuye a su titular un haz de facultades consistente en diversos poderes jurídicos cuyo ejercicio impone a terceros deberes jurídicos, que no se contienen en el derecho a la intimidad, y que sirven a la capital función que desempeña este derecho fundamental: garantizar a la persona un poder de control sobre sus datos personales", incluyendo "el derecho a que se requiera el previo consentimiento para la recogida y uso de datos personales, el derecho a saber y ser informado sobre el destino y uso de esos datos y el derecho a acceder, rectificar y cancelar dichos datos. En definitiva, el poder de disposición sobre los datos personales" 55 .

La separación de ambos derechos, a nivel de la norma constitucional, tenía por objeto evitar las confusiones entre la autodeterminación informativa y otros derechos constitucionales. El senador Harboe planteó que la doctrina y la jurisprudencia habían reconocido el derecho "en base a un concepto amplio del derecho de propiedad, partiendo de la libertad de expresión, o del derecho a la intimidad de las personas y sus familias, pero sin que se haya logrado una formulación autónoma que sea plenamente funcional" ${ }^{56}$. El planteamiento tiene asidero en la misma génesis de la Constitución de 1980. En efecto, tal como ha argumentado Anguita, la Comisión de Estudios para la Nueva Constitución no advirtió los riesgos provenientes del desarrollo tecnológico y del tratamiento masivo y automatizado de datos personales ni tampoco hizo un esfuerzo de deslindar la noción de privacidad (en términos de privacy) ${ }^{57}$, tal como se entiende en el mundo anglosajón, el cual incluye una noción de privacidad informativa (information privacy) ${ }^{58}$, en línea con el contenido de la autodeterminación informativa.

\footnotetext{
53 HDL, pp. 32, 35 y 104.

54 HDL, p. 4.

55 STCE, 254/1993, FJ. 7.

$56 \mathrm{HDL}, \mathrm{p} .11$.

57 Anguita (2007), pp. 136-7.

58 Sobre information privacy, véase Solove (2008), pp. 101-70; Allen (2011), pp. 156-62; Francis \& FranCIS (2017), pp. 30-61; BRIDges (2017), pp. 133-78; SOlOve \& SChWARTZ (2017), pp. 31-46; SOlOVE \& SCHWARTZ (2018), pp. 2-3. Sobre la discusión de la conexión entre privacidad e intimidad en Chile y las taxonomías de intervención en la vida privada, con los antecedentes comparados, véase por todos FigueroA (2014), pp. 23-48; 157 y ss.
} 
Este intento de separación en los debates legislativos no estuvo exento de confusiones. Las confusiones se dieron tanto respecto de la ubicación de la autodeterminación informativa en la Constitución, como de la relación entre el derecho a la privacidad y la autodeterminación informativa. En primer lugar, los debates legislativos dan cuenta que la razón de ubicar sistemáticamente a la autodeterminación informativa en el art. 19 No. 4 de la Constitución se basaba en la conexión - no del todo aclarada - con el derecho al respeto y protección de la vida privada o, derechamente, con la intimidad. En efecto, como se lee en diversos apartados de la tramitación legislativa, el derecho a la protección de datos personales se entendió como una "dimensión moderna" 59 del derecho a la protección de la vida privada. En este sentido, algunos incluso plantearon que la privacidad era un "derecho madre" respecto de la autodeterminación informativa y por ello se justificaba "anclar" al segundo en la norma del primero ${ }^{60}$. Por otro lado, mientras que algunos autores de la moción defendieron la autonomía del derecho a la protección de datos personales frente a la privacidad ${ }^{61}$, por el otro, para evitar que el reconocimiento del derecho fuese mezclado con el derecho de propiedad, afirmaron que "el derecho de protección de datos personales emana del derecho a la privacidad", siendo "una proyección de la intimidad pero sin ser idénticos" 62 .

Es necesario, al menos someramente, explicar el concepto y fundamento de la autodeterminación informativa. En términos simples, la autodeterminación informativa se ha entendido como el "control que ofrece a las personas sobre el uso por terceros de información sobre ellas mismas" "33. El rasgo de autodeterminación como autocontrol es expresión de su fundamento: el libre desarrollo de la personalidad. Normativamente, garantizar una autonomía decisional respecto de la información personal de un individuo es lo que posibilita el libre desarrollo de la personalidad. Éste es el fundamento de las sentencias del Tribunal Constitucional Federal alemán, revisadas en la sección anterior. En efecto, la cláusula constitucional de dignidad, entendida en su dimensión de autonomía ${ }^{64}$, obliga al Estado a tratar a los miembros de la comunidad política como personas capaces de autode-

59 HDL, pp. 31-2.

$60 \mathrm{HDL}$, p. 60.

61 Por ejemplo, el senador Harboe, HDL, pp. 43 y 59.

62 HDL, pp. 89-90.

63 Murillo (2009), pp. 11-2. Véase también a Westin (1967), p. 142; Tzanou (2017), pp. 12-31

64 García et Al. (2016), p. 86. En el ámbito europeo, Tzanou (2017), p. 29; González Fuster (2014), pp. 23-6. 
terminarse, entre otras cosas, en el uso de su información personal, con el objeto de que puedan programar su propio plan de vida ${ }^{65}$. En otros términos, tratarlas como fines en sí mismos. Por ello, la autodeterminación informativa garantizaría "la facultad del individuo de decidir básicamente por sí sólo sobre la difusión y utilización de sus datos personales" ${ }^{16}$. Esto impide la instrumentalización de las personas y reducirlas a meros medios para alcanzar fines privados o estatales ${ }^{67}$.

Privacidad y protección de datos personales tienen puntos de intersección pero la intención de la reforma fue, precisamente, separarlos como derechos independientes ${ }^{68}$. La idea de autocontrol sobre el tratamiento de datos personales permite dar cuenta de mejor forma que un dato personal puede eventualmente ser divulgado públicamente, siempre que dicho tratamiento se ajuste a las reglas básicas de protección de datos personales. Por ejemplo, el nombre, dirección o teléfono de una persona natural, contenido en una guía telefónica, es el ejemplo típico de un dato contenido en una fuente accesible al público, lo que habilita su tratamiento sin necesidad de consentimiento del titular (art. 2, letra i) y art. 4, inc. $5^{\circ}$, Ley No. 19.628). Si para el tratamiento de ese dato personal debe respetarse el principio de finalidad, es una discusión que poco o nada tiene con el respeto y protección de la vida privada pero que sí está directamente relacionada con la autodeterminación informativa y su tutela ${ }^{69}$. Otro ejemplo son las facultades que el derecho entrega a su titular, con independencia de la licitud del tratamiento que un tercero haga respecto de los datos personales en cuestión. En términos sencillos, una empresa puede haber celebrado un contrato con un individuo y en virtud de aquello efectuar el tratamiento de datos personales. Pero el titular siempre podrá revocar el consentimiento o ejercer el derecho de oposición o cancelación sobre los datos personales que esa empresa está tratando. Esta dimensión del derecho a la autodeterminación informativa no tiene punto de conexión necesario con el derecho al respeto y protección de la vida privada.

65 En el mismo sentido, Anguita (2016), pp. 34-5.

66 Piñar Mañas (2009), p. 89.

67 CoHen (2000), p. 1408.

68 Sobre el debate en el derecho comparado, véase Tzanou (2017), pp. 21 y ss.

69 Es una de las cuestiones que, precisamente, se está discutiendo en el proyecto de ley que reforma la Ley No. 19.628. Véase [proyecto de ley que regula la protección y el tratamiento de los datos personales y crea la Agencia de Protección de Datos Personales (Boletín $\mathrm{N}^{\circ}$ 11.144-07) y el proyecto de ley sobre protección de datos personales (Boletín $\mathrm{N}^{\circ}$ 11.092-07). [Fecha de consulta: 25.03.19]. [Disponible en: https://www.camara. cl/pley/pley_detalle.aspx?prmID=11661\&prmBoletin=11144-07]. 
Por otro lado, la ubicación de la autodeterminación informativa no convierte a éste en un derecho dependiente de la privacidad, al igual que el derecho a la integridad física y síquica es independiente del derecho a la vida, pese a estar ambos recogidos en el mismo inciso (art. 19 No. 1, inc. $1^{\circ}$ de la Constitución). En este sentido, el autocontrol o la decisión autónoma sobre el tratamiento de datos personales, por su titular -con independencia de si la información se encuentra en esferas más o menos públicas o privadas- parece explicar de mejor forma la independencia conceptual y normativa del derecho a la protección de datos personales respecto de la privacidad.

Finalmente, una tercera respuesta es que el reconocimiento constitucional expreso del derecho a la protección de datos personales puede tener justificación desde el punto de vista de las garantías del derecho. Tal como se constata en la discusión legislativa, deliberadamente se buscó garantizar el ejercicio legítimo de la autodeterminación informativa a través del recurso de protección ${ }^{70}$, desechando las voces minoritarias que se opusieron a ello $^{71}$.

\section{2. ¿Mucho o poco? La densidad normativa del derecho a la autodeterminación informativa}

El reconocimiento del derecho a la protección de datos personales sufrió un importante cambio en el segundo trámite constitucional y determina la extensión del derecho en sí y de su contenido iusfundamentalmente protegido. El cuadro 1 esquematiza las distintas versiones del derecho durante la tramitación legislativa.

El cuadro muestra cómo el texto original cambia considerablemente con la intervención de la Presidenta de la República. El primer gran ajuste fue la eliminación de las bases de licitud para el tratamiento de datos personales. En la moción original, el derecho a la protección de datos personales incluía la constitucionalización de los derechos ARCO -enunciados en la sección anterior- y, adicionalmente, establecía un sistema binario de licitud del tratamiento, fundado en el consentimiento y en la autorización legal. En el primer trámite constitucional, se

70 HDL, pp. 11, 45, 52, 88, 127 y 130.

71 El Senador Bianchi presentó una indicación que buscaba excluir el derecho del ámbito de aplicación del artículo 20 de la Constitución, que fue rechazada durante el primer trámite constitucional (HDL, p. 45). Por otro lado, Claudio Magliona, profesor de la Universidad de Chile y abogado de Google en Chile, no era partidario del recurso de protección, en esta materia, prefiriendo la vía administrativa ante un órgano garante especializado. HDL, p. 40. 


\section{Cuadro 1. Versiones del reconocimiento del derecho a la protección de datos personales durante la tramitación legislativa}

\begin{tabular}{|l|l|}
\hline Texto de la moción & $\begin{array}{l}\text { Art. 19: La Constitución asegura a todas las personas: [...] } \\
\text { No. 4. El respeto y protección a la vida privada y a la honra de la persona y su } \\
\text { familia. } \\
\text { Toda persona tiene derecho a la protección de sus datos personales y obtener su } \\
\text { rectificación, complementación y cancelación, si estos fueren erróneos o afectaren sus } \\
\text { derechos, como asimismo a manifestar su oposición, de acuerdo con las disposiciones } \\
\text { establecidas en la ley. } \\
\text { Su tratamiento sólo podrá hacerse por ley o con el consentimiento expreso del titular; } \\
\text { [...] }\end{array}$ \\
$\begin{array}{l}\text { Texto aprobado } \\
\text { en primer trámite } \\
\text { constitucional }\end{array}$ & $\begin{array}{l}\text { Art. 19: La Constitución asegura a todas las personas: [...] } \\
\text { No. 4. El respeto y protección a la vida privada y a la honra de la persona y su } \\
\text { familia. Asimismo, la protección de sus datos personales, el derecho a acceder a ellos } \\
\text { y a obtener, en la forma que determine la ley, su rectificación, complementación y } \\
\text { cancelación, si éstos fueren erróneos o afectaren sus derechos. } \\
\text { El tratamiento, circulación y traspaso de esos datos deberá realizarse en la forma y } \\
\text { condiciones que fije la ley; [...] }\end{array}$ \\
\hline $\begin{array}{l}\text { Texto de la indi- } \\
\text { cación sustitutiva } \\
\text { de la Presidenta de } \\
\text { la República, en } \\
\text { segundo trámite } \\
\text { constitucional }\end{array}$ & $\begin{array}{l}\text { Art. 19: La Constitución asegura a todas las personas: [...] } \\
\text { No. 4. El respeto y protección a la vida privada y a la honra de la persona y su } \\
\text { familia. Asimismo, la protección de sus datos personales. El tratamiento y protección } \\
\text { de estos datos se efectuará en la forma y condiciones que determine la ley; [...] }\end{array}$ \\
\hline $\begin{array}{l}\text { Texto publicado } \\
\text { como Ley de Refor- } \\
\text { ma Constitucional } \\
\text { No. 21.og6 }\end{array}$ & $\begin{array}{l}\text { Art. 19: La Constitución asegura a todas las personas: [...] } \\
\text { No. 4. El respeto y protección a la vida privada y a la honra de la persona y su fa- } \\
\text { milia, y asimismo, la protección de sus datos personales. El tratamiento y protección } \\
\text { de estos datos se efectuará en la forma y condiciones que determine la ley; [...] }\end{array}$ \\
\hline Fuente: Elaboración propia en base a los antecedentes de la HDL. \\
\hline
\end{tabular}

criticó que la Constitución estableciere la exigencia de consentimiento "expreso" para el tratamiento de datos personales. En particular, el profesor Magliona sostuvo que "en el derecho comparado no es 'consentimiento expreso o tácito', sino que 'consentimiento inequívoco"' y, en virtud de lo anterior, "recomendó eliminar la referencia al consentimiento, porque éste es un concepto que ha ido variando en el tiempo"72. La Comisión de Constitución, Legislación, Justicia y Reglamento del Senado concordó con dicho criterio y modificaron el texto original de la moción para hacer una reserva de ley general respecto del derecho ${ }^{73}$. 
El segundo cambio fue aún más profundo: a partir de la indicación sustitutiva de la Presidenta de la República, se eliminaron todas las referencias a las facultades de los titulares de datos personales, en particular, a los derechos ARCO. Ya en el primer trámite, el Senador Bianchi había presentado una indicación bajo un tenor similar ${ }^{74}$ y el profesor Magliona criticó el nivel de detalle del derecho, lo que podía conducir a "rigideces innecesarias" en la materia ${ }^{75}$. En dicha instancia, tanto el Senador Harboe como el resto de los miembros de la Comisión "estimaron conveniente que el texto constitucional mencione expresamente los derechos 'ARCO' (acceso, rectificación, complementación y cancelación de datos personales), con el fin de que el legislador los regule y desarrolle posteriormente" 76 .

Sin embargo, en segundo trámite constitucional, el Senador Harboe cambia de criterio y apoyó la indicación del Ejecutivo. En particular, sostuvo que "durante la tramitación del proyecto se ha ido revelando que no es adecuado incorporar en el texto constitucional, que tiene vocación de estabilidad en el tiempo, algunos de los elementos que son parte de la protección de datos", estando de acuerdo con "establecer una protección más genérica" 7 . El ejemplo que fue citado era el derecho a la portabilidad de datos personales, que no se encuentra actualmente recogido en la Ley 19.628 y que no había contemplado la moción original y que hace un tiempo atrás no existía ${ }^{78}$. Por estas razones, los legisladores estimaron conveniente simplificar la formulación de la autodeterminación informativa, eliminar las referencias a los derechos ARCO y hacer una remisión al legislador para que desarrolle el contenido del derecho, tal como consta en el texto publicado como ley de reforma constitucional.

Cabe hacer notar que, dentro de la tramitación, se objetó la simplificación y vaciamiento del contenido del derecho en cuestión. En particular, el profesor Manuel Núñez citó el caso de la Carta de los Derechos Fundamentales de la Unión Europea, en donde el derecho a la protección de datos personales establece un "contenido mínimo y demás cualidades del derecho que también incluye una agencia de protección de datos"79. Al revisar la formulación del derecho en la Car-

74 HDL, p. 38 y 42.

75 HDL, p. 40.

76 HDL, p. 42.

77 HDL, p. 60 y 63.

78 HDL, p. 6o, 91, 93 y 96.

79 HDL, p. 93. 
$\mathrm{ta}^{80}$, es posible identificar los siguientes elementos en la configuración del derecho: i) se establecen los principios de licitud, lealtad y finalidad; ii) se establecen los derechos de acceso y rectificación; y iii) se establece una garantía institucional reservada a una autoridad de control independiente ${ }^{81}$. Como bien apuntó Núñez, no es extraño a la Constitución chilena el individualizar un órgano a cargo de la supervisión de un derecho fundamental, tal como acontece con el Consejo Nacional de Televisión a propósito de la libertad de opinión e información (art. 19 No. 12, inc. $6^{\circ}$ de la Constitución) ${ }^{82}$.

Es criticable la fundamentación del cambio de criterio en la densidad normativa del reconocimiento del derecho a la protección de datos personales. En primer lugar, el reconocimiento de ciertas facultades para el titular del derecho -como eran los derechos ARCO- no impide que, dada una correcta formulación técnica en la redacción de la norma, el legislador pueda complementar el contenido iusfundamentalmente protegido del derecho. En otros términos, la mención de algunas facultades consideradas como esenciales no impide el reconocimiento normativo posterior de otras, por parte del legislador. En segundo lugar, si el único ejemplo citado para fundamentar el vaciamiento de contenido es el derecho a la portabilidad de los datos personales, una alternativa obvia era agregar dicha facultad en la norma constitucional y remitir al legislador para su desarrollo o complementación ${ }^{83}$. Por último, que esta materia sea especialmente propensa a los desarrollos de la técnica, no impide generar formulaciones neutras que pre-

80 Carta de los Derechos Fundamentales de Unión Europea 2000/C 364/01. [Fecha de consulta: 19.06.19] [Disponible en:

http://www.europarl.europa.eu/charter/pdf/text_es.pdf].

81 "Artículo 8 - Protección de datos de carácter personal.

1. Toda persona tiene derecho a la protección de los datos de carácter personal que le conciernan.

2. Estos datos se tratarán de modo leal, para fines concretos y sobre la base del consentimiento de la persona afectada o en virtud de otro fundamento legítimo previsto por la ley. Toda persona tiene derecho a acceder a los datos recogidos que le conciernan y a obtener su rectificación.

3. El respeto de estas normas estará sujeto al control de una autoridad independiente."

82 HDL, p. 93.

83 Es, por lo demás, la técnica empleada en el art. 19 No. 7, letra f), que regula la prohibición de autoincriminación. Nótese la técnica de reserva legal complementaria de dicha disposición: "[n]o n las causas criminales no se podrá obligar al imputado o acusado a que declare bajo juramento sobre hecho propio; tampoco podrán ser obligados a declarar en contra de éste sus ascendientes, descendientes, cónyuge y demás personas que, según los casos y circunstancias, señale la ley". La Constitución especifica quiénes son parte del contenido de la prohibición -el titular y éste en relación con sus ascendientes, descendientes y cónyuge- y habilita al legislador a complementar la regla. Por ello, por ejemplo, el legislador estaría autorizado a definir que la prohibición se puede extender al conviviente civil, figura que no existía al momento de promulgarse la Constitución de 1980. 
serven un detalle mínimo del contenido del derecho al tiempo que prevenga la obsolescencia tecnológica. La inviolabilidad de las comunicaciones privadas, en la formulación del art. 19 No. 5, presenta dicha ductilidad ${ }^{84}$. Pese a estas razones, los legisladores optaron por simplificar la formulación del derecho y hacer una amplia remisión al legislador para la regulación del mismo.

\subsection{Dueños de nuestros datos: ¿titularidad o propiedad?}

Para cerrar esta sección, es pertinente revisar el último dilema relevante en la configuración del derecho a la protección de datos personales. ¿Cuál es la relación jurídica entre una persona y sus datos personales? En el debate legislativo hubo dos tesis encontradas: la relación de titularidad y la relación de dominio privado.

La discusión sobre el dominio privado respecto de los datos personales no es algo ajeno a la discusión comparada ${ }^{85}$. En efecto, en el ámbito estadounidense la discusión sobre la asignación de derechos de propiedad forma parte importante del debate sobre la protección de datos personales ${ }^{86}$, mientras que en el ámbito europeo es una cuestión distinta ${ }^{87}$, dada la trayectoria regulatoria que funda la protección de datos personales en base a la tutela de un derecho fundamental ${ }^{88}$.

Es indudable que una base de datos puede constituir un activo en términos económicos. Los datos personales son información y, en tanto tal, proporcionan "una ventaja competitiva que se transforma en ingresos" y constituyen commodity con alta valoración en el mercado ${ }^{89}$. Los estudios sobre el valor que le dan las personas a la protección de sus datos personales y, en términos más generales, respecto de su privacidad ${ }^{90}$, permiten diagnosticar y diseñar esquemas regulatorios que den cuenta de la racionalidad limitada de los titulares de datos, las asimetrías de información en la autorización de tratamiento de datos personales, los costos

84 Álvarez (2019), pp. 97 y ss.

85 Véase, por todos, Purtova (2009).

86 Brandeis \& Warren (1890): 200-206; Westin (1967); Lessig (2002); Schwartz (2004); Solove (2004), pp. 76-92; Purtova (2009); Victor (2013); entre otros.

87 Sin embargo, véase los aportes de Purtova (2009); Purtova (2015); Malgieri (2016); Bouchagiar \& Bоттіs (2018) en materia de propiedad de datos personales.

88 González Fuster (2014), pp. 21-27; WaCKs (2015), pp. 62-65; Tzanou (2017), pp. 7-44.

89 Frigerio (2018), pp. 51-2.

90 Winegar \& SUNSTEIN (2019). 
de transacción que afectan a los titulares y las externalidades negativas propias del intercambio de datos personales ${ }^{91}$.

En el ámbito chileno, la discusión doctrinal sobre propiedad de datos personales ha sido bastante más acotada ${ }^{92}$. Por ejemplo, Raúl Bertelsen ha sostenido que "[c]onforme a las normas constitucionales vigentes resulta indiscutible que la persona que efectúa operaciones de tratamiento de datos y elabora un registro o banco de los mismos, tiene un derecho de propiedad sobre la base de datos que goza de reconocimiento y protección constitucional"93. Bertelsen afirma categóricamente que:

"El contenido de una base de datos puede, en efecto, representar un activo de gran valor patrimonial y de ahí la importancia de reconocer a su dueño el ejercicio exclusivo de las tradicionales facultades del dominio, esto es el uso, goce y disposición, quien podrá celebrar a su respecto los actos y contratos que permita la legislación vigente y no podrá ser privado de su propiedad sino a través del correspondiente proceso expropiatorio"94.

Esta tesis contrasta directamente con el debate comparado. La posición de Bertelsen tiene por objeto resguardar la propiedad del responsable del tratamiento sobre el fichero o base de datos y no la relación de dominio, por parte del titular, respecto de sus datos personales. Bertelsen invierte los términos del debate: en vez de discutir si los datos personales pueden ser "propiedad" de una persona, el argumento esgrime que el responsable es "dueño" de los datos que trata en una base de datos.

La tesis de la titularidad permite explicar de mejor forma el contenido de la autodeterminación informativa como autocontrol. En efecto, los modelos de data ownership son difíciles de acomodar con figuras como la revocación del consentimiento en el tratamiento de datos personales y, en general, con el ejercicio de los derechos ARCO del titular en relación con el responsable del tratamiento. La cesión de un dato personal no es irrevocable y el titular siempre puede ejercer sus derechos en contra de quien está tratando dichos datos. Además, la titularidad

91 Frigerio (2018), pp. 55-59.

92 Para un intercambio epistolar reciente, post reforma constitucional de 2018, véase Contreras (2019).

93 Bertelsen (2001), p. 121.

94 Bertelsen (2001), p. 121. 
del dato personal permite dar cuenta de los deberes que tiene el responsable en relación con dicha información personal95.

La opinión de Bertelsen debe entenderse superada por la reforma constitucional. El debate del proyecto de ley de reforma constitucional despejó explícitamente el punto en controversia, durante el segundo trámite en la Cámara de Diputados ${ }^{96}$. La reforma tuvo por objeto determinar una relación jurídica de titularidad de la persona en relación a sus datos personales. En efecto, se expresó en diversas partes del debate que la información personal es de titularidad de los individuos ${ }^{97}$. Algunos parlamentarios emplearon impropiamente la expresión "propiedad" como una forma retórica de afirmar el control de las personas sobre su información personal ${ }^{98}$. Por ejemplo, el senador Larraín descarta que el Estado y sus autoridades sean "dueñas de la información"99, o el senador Zaldívar, quien preguntaba retóricamente: “ ¿ [y] quién es el dueño de los datos personales? La persona" ${ }^{100}$. En ambos casos, la idea de propiedad es metafóricamente empleada para efectos de afirmar la titularidad de la información personal y para garantizar el autocontrol de la misma y no con el objeto de traducir el derecho a la autodeterminación informativa en facultades o atributos del dominio privado, como se encuentra establecido en el artículo 19 No. 24 de la Constitución. Otras opiniones reafirman este uso retórico de la expresión "propiedad" como equivalente de autocontrol de la información ${ }^{101}$.

Más allá de estos usos impropios del concepto de propiedad, el debate sobre el dominio de los datos personales se dio efectivamente a partir de una indicación presentada el 2018, en el segundo trámite constitucional de la reforma, patrocinada por la diputada Del Real y los diputados Álvarez-Salamanca, Bobadilla, Fuenzalida, García, Kort, Mellado, Noman, Norambuena, Paulsen, Prieto y Von Mühlenbrock ${ }^{102}$. La indicación proponía establecer el siguiente inciso: "Para es-

95 Véase, por ejemplo, en materia del deber de información, a MAtus \& Montecinos (2006), pp. 123 y ss. 96 HDL, pp. 84 y ss.

$97 \mathrm{HDL}$, p. 34, 86, 89 y $92-93$.

98 HDL, p. 27, 53, 64 y 110.

99 HDL, p. 27.

100 HDL, p. 53.

101 Por ejemplo, la diputada Molina argumentó que "[l] as personas son dueñas de sus datos personales y solo ellas tienen la potestad para autorizar su uso" (HDL, p. 64) o la diputada Troncoso, que argumentó que "el país necesita dar garantías a nuestros compatriotas sobre los datos personales, que hoy, lamentablemente, existen falencias respecto de la propiedad de estos datos" (HDL, p. 110).

102 HDL, p. 84. 
tos efectos, la Constitución asegurará la propiedad de los datos personales a su titular"103.

El debate en la Comisión de Constitución de la Cámara de Diputados rechazó esta inclusión. En primer término, se planteó si la relación jurídica respecto de los datos personales podía ser calificada como una "especie de propiedad", al tenor de lo dispuesto en el art. 583 del Código Civil, esto es, respecto de la propiedad sobre cosas incorporales ${ }^{104}$. En términos mucho más directos, el diputado Fuenzalida negó la relación de titularidad entre una persona y sus datos personales: “[n]o existe la titularidad, existe el dominio, y cuando se suscriben contratos con los bancos $\mathrm{u}$ otras instituciones obviamente se entregan datos, que son personales, que son un bien y como un bien, eran transables"105. Para algunos diputados, la protección de los datos personales no sería efectiva si se reconocían bajo la idea de propiedad privada, lo que podía generar conflictos respecto del tratamiento que el sistema público o privado puede hacer de esos datos ${ }^{106}$, mientras otro planteó sus interrogantes respecto a la posibilidad de expropiación si los datos personales estaban sometidos al régimen de propiedad de la Constitución ${ }^{107}$.

El diputado Hirsch planteó que debía rechazarse la indicación porque la relación jurídica de los datos personales con una persona es una relación de titularidad $^{108}$. Para Hirsch, la titularidad se entendía "como derecho de autodeterminación”, para evitar transferencias de dominio, "pues la idea de propiedad llevaría las cosas ahora 'a otra cancha' y podía generar un problema no menor a futuro con la transactividad de los datos, cuestión diferente con el concepto de titularidad, pues no era transferible esa titularidad"109.

La tesis de Hirsch tuvo el apoyo de los invitados en una nueva sesión donde se zanjó el asunto. En efecto, el senador Harboe asistió a la comisión de la Cámara y sostuvo que el derecho a la protección de datos personales "emana del derecho a la intimidad y no del derecho a la propiedad, por cuanto la propietarización de este derecho podría afectar la naturaleza del mismo"110. La opinión fue secundada

103 HDL, p. 84.

104 HDL, p. 86 (opinión del diputado Alessandri).

105 HDL, p. 87 (opinión del diputado Fuenzalida).

106 HDL, p. 86 (opinión del diputado Saffirio).

107 HDL, p. 87 (opinión del diputado Gutiérrez).

108 HDL, pp. 86-87 (opinión del diputado Hirsch).

109 HDL, p. 87 (opinión del diputado Hirsch).

110 HDL, p. 89 (opinión del senador Harboe). 
por el resto de los invitados a la comisión, como la consejera del Consejo para la Transparencia, Gloria de la Fuente ${ }^{111}$, el Presidente del Instituto Chileno de Derecho y Tecnología, Raúl Arrieta ${ }^{112}$ y la opinión del profesor Manuel Núñez ${ }^{113}$. Con estas consideraciones, la comisión rechazó la indicación y reafirmó la idea de titularidad de una persona en relación a sus datos personales.

\section{Los desafíos tras el reconocimiento constitucional de la autodeterminación informativa}

En este último apartado se revisan los desafíos que se abren tras el reconocimiento constitucional explícito de la autodeterminación informativa. Se trata de las cuestiones que no fueron suficientemente abordadas ni zanjadas en la discusión legislativa y que tendrán impacto en la reforma a la Ley No. 19.628 y en la interpretación y aplicación del derecho a la protección de datos personales en casos concretos. En particular, se analizan dos desafíos. El primero dice relación el tipo de remisión o reserva al legislador del mandato de protección de datos personales. La relación entre el reconocimiento del derecho y la remisión al legislador requiere ser pensada en términos tales que sea posible identificar un contenido del derecho, por un lado, y de habilitar al legislador democrático la elección de los medios y mecanismos de tutela del mismo. El segundo desafío se refiere a la garantía de la autodeterminación informativa y, en particular, a la protección del derecho a través del recurso de protección, a través del habeas data y a través de una agencia especializada como autoridad de control.

\subsection{La reserva legal de la protección de datos personales}

La fórmula de reconocimiento del derecho estableció un mandato amplio al legislador para proteger los datos personales de sus titulares. En particular, la Constitución ordena al legislador a fijar la "forma y condiciones" del tratamiento y protección de tales datos. Si bien es claro que la reforma buscó resguardar la autodeterminación informativa del titular sobre sus datos personales, la eliminación a los derechos ARCO puede plantear problemas interpretativos a la hora de regular legalmente el ejercicio del derecho.

111 HDL, p. 92 (opinión de la consejera De la Fuente).

112 HDL, pp. 92-3 (opinión de Arrieta).

113 HDL, p. 93 (opinión del profesor Núñez). 
Una de las cuestiones más relevantes a contestar es si los derechos ARCO pueden ser considerado parte del contenido esencial del derecho a la protección de datos personales o no. En otros términos, ¿puede entenderse la renuncia al detalle de los derechos ARCO en la disposición constitucional dejaría un margen de acción del legislador tan amplio que podría incluso prescindir de ellos a nivel de la regulación legal? ¿Cuál es el margen de acción del legislador?

En relación a la revisión de los antecedentes del proyecto y de los principales cambios que éste sufrió, durante su tramitación, es conveniente tener presente lo siguiente para responder dichas preguntas. La razón de aceptar la indicación del Ejecutivo, que eliminó la especificidad de los derechos ARCO, fue evitar la obsolescencia del texto constitucional, tal como se revisó más arriba ${ }^{114}$. Si bien en un momento se pensó en una redacción con los derechos de acceso, rectificación, cancelación y oposición, luego se argumentó que el texto no daría cuenta del derecho a la portabilidad, que hoy se está discutiendo como parte de las reformas a la Ley No. 19.628 y en concordancia con los estándares internacionales ${ }^{115}$. El argumento no era conclusivo y existían diversas técnicas legislativas para entender a los derechos ARCO, como parte del contenido del derecho, por un lado, y evitar la obsolescencia en el tiempo con una remisión al legislador o una cláusula abierta. Lo que es claro es que, al momento de tramitar la reforma constitucional, no estuvo en cuestionamiento que los derechos ARCO formaban parte del contenido del derecho a la protección de datos personales ${ }^{116}$.

Si lo anterior es correcto, entonces el derecho a la protección de datos personales contempla como mínimo el respeto de los derechos ARCO y éstos podrían ser considerados parte del núcleo esencial del mismo, conforme a la garantía del artículo 19 No. 26 de la Constitución. Por otro lado, el mandato al legislador está orientado a reconocerlos explícitamente y regularlos de forma tal de hacer posible dicho ejercicio ${ }^{117}$. Esta afirmación, además, es coherente con el reconocimiento implícito que ya hizo el Tribunal Constitucional y se revisó más arriba ${ }^{118}$. Adicionalmente, la reserva de ley podría complementar este contenido esencial con el

114 Véase supra III, 2.

115 Véase el Boletín $\mathrm{N}^{\circ}$ 11.144-07 ya citado. En el plano europeo, la regla se encuentra en el art. 52 RGPD.

$116 \mathrm{Si}$ uno observa las pocas críticas a la densidad normativa del proyecto original, éstas apuntaban a la técnica de reconocimiento del derecho y no a cuestionar a los derechos ARCO como parte del derecho a la protección de datos personales. Véase, por ejemplo, la opinión del Prof. Magliona en HDL, p. 40.

117 HDL, p. 40, 89 y 91.

118 Véase supra II, 3. 
reconocimiento de nuevas facultades de la autodeterminación informativa, como es el derecho a la portabilidad de los datos personales ${ }^{119}$. En este plano, se trataría de una reserva de ley complementaria del derecho ${ }^{120}$.

\subsection{La garantía de la autodeterminación informativa}

Por último, es necesario atender al debate sobre la garantía de la autodeterminación informativa. Como es conocido por la teoría general de derechos fundamentales, el concepto de garantía en términos amplios se entiende como aquellos mecanismos de protección de un derecho, sean o no jurisdiccionales ${ }^{121}$. El debate de la reforma constitucional profundizó sobre los mecanismos de tutela del derecho a la protección de datos personales. En primer término, el reconocimiento explícito del derecho tenía por objeto evitar cualquier cuestionamiento al carácter iusfundamental del derecho. Pero, adicionalmente, se debatió sobre la procedencia del recurso de protección y la necesidad de contar con una autoridad de control en materia de protección de datos personales, con competencia para conocer del habeas data. Ambos aspectos se revisan a continuación.

En relación al recurso de protección, la decisión de reconocer explícitamente el derecho a la autodeterminación informativa en el art. 19 No. 4 de la Constitución tenía entre otros objetivos el de asegurar su tutela a través de la acción o recurso de protección, establecido en el art. 20 de la Constitución. En efecto, tanto diputados como senadores estimaban que el recurso de protección sería un medio expedito, rápido y eficaz en la protección del nuevo derecho ${ }^{122}$. Esta necesidad no se encontraba argumentada o respalda especialmente, pero puede deberse a la insatisfacción relativa a un habeas data como acción legal jurisdiccional, que exige el patrocinio de abogado y se tramita ante los tribunales ordinarios ${ }^{123}$. Tal como en su momento lo evaluó la Cámara de Diputados, el procedimiento actual de habeas data establecido en la Ley No. 19.628 no es eficaz para proteger los derechos de las personas, ya que "el titular de los datos tiene derecho a recurrir al juez de

119 HDL, pp. 93.

120 GARCía (2004), pp. 173-178.

121 Véase, por todos, García et AL. (2016), pp. 511-513, Paredes (2014), pp. 15 y ss.

122 HDL, pp. 49, 51, 89-9o (opinión del senador Harboe), 52 (opinión del senador Coloma), 53 (opinión del senador Zaldívar), 88 (opinión del diputado Saffirio), 101 (opinión del diputado Soto), 127 (opinión del senador Huenchumilla) y 130 (opinión del senador Elizalde).

123 Sobre el habeas data, véase PuCinelli (1999), pp. 333-366; Jervis (2003); GARRIDo (2013); SAlas (2014); PARedes (2014). 
letras en lo civil del domicilio del responsable", lo que "implica un costo para el afectado y un tiempo de tramitación considerable que no se ajusta a las exigencias de los actuales sistemas de información" ${ }^{124}$.

Sin perjuicio de lo anterior, en el debate se hizo presente la inquietud sobre cómo resolver la compatibilidad de acciones entre el recurso de protección y la acción de habeas data, especialmente si la Ley No. 19.628 es reformada. En efecto, el art. 20 dispone expresamente que es una acción que puede ser interpuesta "sin perjuicio de los demás derechos que pueda hacer valer ante la autoridad o los tribunales correspondientes". La doctrina constitucional ha ratificado la compatibilidad del recurso de protección con otras acciones o recursos ${ }^{125}$-en virtud del propio texto constitucional-, sin perjuicio de las excepciones en que el legislador ha previsto expresamente una incompatibilidad, como es en la legislación aduanera, tributaria y antidiscriminatoria ${ }^{126}$. Sobre este punto, el profesor Magliona sostuvo que "no era partidario que la protección de datos personales esté amparada por la acción cautelar de derechos que establece el artículo 20” y recalcó que era conveniente tener una institucionalidad administrativa especializada para conocer la acción de habeas data ${ }^{127}$. Por otra parte, la consejera del Consejo para la Transparencia, Gloria de la Fuente, advirtió que el recurso de protección, si bien puede ser interpuesto sin necesidad de contar con patrocinio de un abogado, para alegar la causa sí se requiere de representación por parte de un abogado y la decisión del recurso no permite generar resolución de problemas con alcance general, como sí se puede lograr a través de las potestades de una autoridad de protección de datos personales ${ }^{128}$.

Estas preocupaciones son válidas de cara a una futura reforma de nuestra legislación de protección de datos personales. Una de las preguntas básicas es si la reforma contemplará una autoridad de control en esta materia y cómo se conjugará el procedimiento de habeas data con la acción de protección, en el evento de su aprobación. Por ello, durante toda la reforma pero especialmente a partir del segundo trámite, se manifiesta la preocupación de los parlamentarios de tener

\footnotetext{
124 Cámara de Diputados (2016), p. 84. En la misma línea, Jervis (2003), p. 26 y Garrido (2013), p. 17; Arrieta (2009), pp. 20-21.

125 Verdugo et Al. (2002), p. 346; Cea (2008), pp. 685-686; Aldunate (2009), p. 363; Paredes (2014), p. 124; García ET AL. (2016), p. 39.

126 HENRÍQUEZ (2018), p. 17.

127 HDL, p. 40.

128 HDL, p. 92.
} 
claridad sobre la garantía del derecho a través de una agencia especializada ${ }^{129}$. La discusión presentó el debate que hoy se está dando en el Congreso, respecto a las características de dicha agencia. En particular, un importante número de parlamentarios indicaron la necesidad de contar con una agencia autónoma e independiente del poder Ejecutivo ${ }^{130}$. Dicho estándar es hoy ineludible, dado el RGPD de la Unión Europea ${ }^{131}$, y ha impactado considerablemente en la discusión de la fisonomía de la agencia que se está creando ${ }^{132}$.

\section{Conclusiones}

El reconocimiento explícito de un nuevo derecho fundamental en la Constitución chilena requiere de una reconstrucción de su contenido, sentido y alcance respecto del legislador, en la eventual reforma a la Ley No. 19.628, y respecto los operadores jurídicos en la resolución de casos concretos. A partir de la examinación crítica de los antecedentes que dieron origen al derecho a la protección de datos personales, es posible concluir lo siguiente:

- La reforma constitucional tuvo por objeto reconocer explícitamente el derecho a la protección de datos personales como un derecho de autodeter-

\footnotetext{
129 HDL, pp. 12 (opinión de Juan Pablo Olmedo); 15 (opinión de José Antonio Viera-Gallo); 26 (opinión del senador Chahuán); 28 (opinión del senador Larraín); 36 (opinión del senador Coloma); 40 (opinión de Claudio Magliona); 50 (opinión del senador Larraín); 78 (opinión del diputado Pardo); 81 (opinión del diputado Longton); 90 y 92 (opinión de la Consejera De la Fuente); 93 (opinión de Manuel Núñez); 95 (opinión del senador Harboe); 97 (opiniones de la Consejera de la Fuente, Raúl Arrieta y el senador Harboe); 114 (opinión de la diputada Olivera); 115 (opinión del diputado Torrealba); 116 (opinión del diputado Longton); 125 (opinión del senador Pugh); y 128 (opinión del senador Coloma).

130 HDL, pp. 26 (opinión del senador Chahuán); 28 (opinión del senador Larraín); 36 (opinión del senador Coloma); 40 (opinión de Claudio Magliona); 50 (opinión del senador Larraín); 78 (opinión del diputado Pardo); 81 (opinión del diputado Longton); 90 y 92 (opinión de la Consejera De la Fuente); 95 (opinión del senador Harboe); 97 (opiniones de la Consejera de la Fuente, Raúl Arrieta y el senador Harboe); 114 (opinión de la diputada Olivera); 116 (opinión del diputado Longton); 125 (opinión del senador Pugh); y 128 (opinión del senador Coloma).

131 Art. 52, RGPD.

$132 \mathrm{Al}$ cierre de este texto, la Comisión de Constitución, Legislación, Justicia y Reglamento del Senado ha aprobado, en primer trámite constitucional y en particular, que el Consejo para la Transparencia será la autoridad de control en materia de protección de datos personales. El proyecto introduce numerosas reformas a la orgánica de la institución y reestructura el Consejo Directivo, reforzando considerablemente el estatuto de autonomía actual y garantizando un modelo fuerte de independencia respecto de los demás poderes públicos. Con la modificación, de aprobarse, el Consejo se pasaría a llamarse Consejo para la Transparencia y la Protección de Datos Personales. Sobre esto véase el Boletín 11.144-07 y su tramitación. [Fecha de consulta: 13.09.19]. [Disponible en: https://www.camara.cl/pley/pley_detalle.aspx?prmID=11661\&prmBoletin=11144-07].
} 
minación informativa, separándolo conceptual y normativamente de otros derechos como el respeto a la vida privada o el derecho de propiedad.

- Estratégicamente, la reforma persiguió un objetivo de forzar al legislador en la regulación y reforma del tratamiento y protección de los datos personales en nuestro país. En efecto, el debate legislativo advirtió la necesidad de continuar el esfuerzo de la reforma constitucional con una modificación integral de Ley No. 19.628.

- La formulación literal del derecho sacrificó la densidad normativa del reconocimiento de derechos ARCO en la Constitución, con el objeto de evitar la obsolescencia del texto constitucional. Sin perjuicio de ello, el contenido constitucionalmente protegido del derecho comprendería los derechos ARCO, sin perjuicio del margen de acción del legislador en su configuración concreta.

- La reforma constitucional descartó un modelo regulatorio de derechos de propiedad para reconocer la relación jurídica entre personas y sus datos personales. Al estructurar el derecho en base a una idea de autodeterminación informativa y autocontrol de la información personal, la relación jurídica de los individuos es de titularidad sobre los datos personales.

- La garantía del derecho actualmente tiene dos vías: la acción de protección -establecido en el art. 20 de la constitución- y el habeas data -recogido en la Ley No. 19.628-. Queda pendiente la definición de una agencia especializada que garantice efectivamente el ejercicio de los derechos propios de la autodeterminación informativa. Sin embargo, existe ya un consenso político en torno a la necesidad de contar con una autoridad de control autónoma e independiente del Gobierno.

\section{Bibliografía citada}

Aldunate, Eduardo (2009): Constitución Política de la República de Chile. Doctrina y Jurisprudencia (Santiago, Thomson Reuters), Tomo I.

Allen, Anita (2011): Unpopular privacy. What must we hide? (Oxford, Oxford University Press).

Álvarez, Daniel (2019): La inviolabilidad de las comunicaciones privadas (Santiago, LOM ediciones). 
Anguita, Pedro (2007): La Protección de Datos Personales y el Derecho a la Vida Privada (Santiago, Edit. Jurídica de Chile).

Anguita, Pedro (2016): Acciones de protección contra Google. Análisis del llamado derecho al olvido en buscadores, redes sociales y medios de comunicación (Santiago, Librotecnia).

Arrieta, Raúl (2009): "Chile y la Protección de Datos Personales: Compromisos Internacionales”, en VV.AA., Chile y la Protección de Datos Personales. ¿Están en Crisis Nuestros Derechos Fundamentales? (Santiago, Ediciones UDP).

BANDA, Alfonso (200o): "Manejo de datos personales. Un límite al derecho a la vida privada”, Revista de Derecho (Universidad Austral de Chile, Vol. 11).

Bertelsen, Raúl (2001): "Datos Personales: Propiedad Privada, Libre Iniciativa Particular y Respeto a la Vida Privada”, en WaHL, Jorge (ed.), Tratamiento de Datos Personales y Protección de la Vida Privada. Estudios sobre la Ley No. 19.628 Sobre Protección de Datos de Carácter Personal (Santiago, Chile. Ediciones Universidad de los Andes).

Bouchagiar, George \& Bottis, Maria (2018): "Personal Data Protection Models: Aspects of Ownership”. [fecha de consulta: 06.08.19] [Disponible en línea: https://www.ssrn.com/abstract=3167011].

Brandeis, Louis D. \& Warren, Samuel D. (1890): “The Right to Privacy”, Harvard Law Review (Vol. 4, No. 5).

BRIDGES, Khiara M. (2017): The poverty of privacy rights (Stanford, Stanford University Press).

Cámara de Diputados (2016): Evaluación de la Ley No. 19.628, Sobre Protección de la Vida Privada. [Fecha de consulta: 08.08.19]. [Disponible en : http://www.evaluaciondelaley.cl/foro_ciudadano/site/artic/20151228/asocfile/20151228124429/informe_final_ley_19628_con_portada.pdf].

CAstro, Monserrat \& MuÑoz, Ana María (2012): “Acceso a la información pública y autodeterminación informativa: publicidad de las remuneraciones de los altos ejecutivos de empresas públicas. El caso de TVN", en Revista Chilena de Derecho y Tecnología (Vol. 1, No. 1).

CEA, José Luis (2008): Derecho Constitucional Chileno (Santiago, Ediciones UC), Tomo II, $2^{\text {a }}$ ed.

Cerda, Alberto (2003): “Autodeterminación informativa y leyes sobre protección de datos", en Revista de Derecho Informático (No. 3). 
Cohen, Julie E. (2000): "Examined lives: Information privacy and the subject as object", en Stanford Law Review (Vol. 52).

Contreras, Pablo (2019): "Propiedad de datos personales". [Fecha de consulta: 07.08.19] [Disponible en: https://www.pcontreras.net/blog/ propiedad-de-datos-personales].

Corral, Hernán (2001): "De los derechos de las personas sobre los responsables de bancos de datos: el hábeas data chileno", en WAHL, Jorge (ed.), Tratamiento de Datos Personales y Protección de la Vida Privada. Estudios sobre la Ley No. 19.628 Sobre Protección de Datos de Carácter Personal (Santiago, Chile. Ediciones Universidad de los Andes).

De la Serna Bilbao, María de las Nieves (2011): "La institucionalización de la protección de datos de carácter personal”, en Arrieta, Raúl \& Reusser, Carlos (coords.), Chile y la Protección de Datos Personales (Santiago, Expansiva UDP).

Donoso, Lorena (2001): "El tratamiento de datos personales en el sector de la educación”, en VVAA, Chile y la protección de datos personales. ¿Están en crisis nuestros derechos fundamentales? (Santiago, Ediciones UDP).

Figueroa, Rodolfo (2014): Privacidad (Santiago, Ediciones UDP).

Francis, Leslie P. \& Francis, John G. (2017): Privacy. What everyone needs to know (Oxford, Oxford University Press).

Frigerio, Catalina (2018): "Mecanismos de regulación de datos personales: Una mirada desde el análisis económico del derecho", en Revista Chilena de Derecho y Tecnología (Vol. 7, No. 2), pp. 45-80.

García, Gonzalo (2014): La Reserva Legal de Derechos Constitucionales: ¿Poder Legislativo contra la Administración? (Santiago, Ediciones UAH, Colección de Investigaciones Jurídicas No. 5).

García, Gonzalo Et AL. (2016): Diccionario Constitucional Chileno (Santiago, Hueders).

Garrido, Romina (2013): "El Habeas Data y la Ley de Protección de Datos Personales en Chile”, en Serie Bibliotecología y Gestión de Información (No 83, junio 2013), disponible [en línea]: http://eprints.rclis.org/19755/1/Serie $\% 20 \mathrm{~N}^{\circ} \% 20$ 83,\%20Junio,\%202013\%20Actualizada.pdf (última visita efectuada 8.8.19).

GonzÁlez Fuster, Gloria (2014): The Emergence of Personal Data Protection as a Fundamental Right of the EU (Heidelberg, Springer).

Henríquez, Miriam (2018): Acción de Protección (Santiago, Der Ed., Cuadernos Jurídicos de la Academia Judicial). 
Jervis, Paula (2003): "Derechos del titular de datos y habeas data en la Ley 19.628", en Revista de Derecho Informático (No. 3).

Jijena, Renato (1992): Chile, la protección penal de la intimidad y el delito informático (Santiago, Editorial Jurídica de Chile).

Lessig, Lawrence (2002): "Privacy as Property", en Social Research (Vol. 69, No. 1), pp. 247-269.

Malgieri, Gianclaudio (2016): “'Ownership' of Customer (Big) Data in the European Union: Quasi-Property as Comparative Solution?", en Journal of Internet Law (Vol. 20, No. 5), pp. 2-17.

Matus, Jessica \& Montecinos, Alejandro (2006): El deber de información y el consentimiento para la cesión de datos personales (Santiago, LexisNexis).

Murillo de la Cueva, Pablo Lucas (2009): "La construcción del derecho a la autodeterminación informativa y las garantías para su efectividad”, en Murillo De la Cueva, Pablo Lucas \& Piñar Mañas, José Luis, El Derecho a la Autodeterminación Informativa (Madrid, Fundación Coloquio Jurídico Europeo).

Nogueira, Humberto (2005): “Autodeterminación informativa y hábeas data en Chile e Información Comparativa", Anuario de Derecho Constitucional Latinoamericano (Año 11, Vol. 2).

Nogueira, Humberto (2012): Derecho Constitucional Chileno (Santiago, Thomson Reuters) Tomo I.

OCDE (1980): "Directrices sobre protección de la privacidad y flujos transfronterizos de datos personales”. [Fecha de consulta: 09.07.19] [Disponible en: http:// www.oas.org/es/sla/ddi/docs/Directrices_OCDE_privacidad.pdf].

OCDE (2009): "Agreement on the Terms of Accession of the Republic of Chile to the Convention on the Organisation for Economic Co-Operation and Development”. [Fecha de consulta: 09.08.19] [Disponible en: https://www.oecd.org/ chile/44381035.pdf].

Paredes, Felipe (2014): La Garantía Jurisdiccional de los Derechos Fundamentales (Santiago, Thomson Reuters).

PIÑar MaÑas, José Luis (2009): "Protección de datos: Origen, situación actual y retos de futuro", en Murillo de la Cueva, Pablo lucas \& Piñar Mañas, José Luis, El Derecho a la Autodeterminación Informativa (Madrid, Fundación Coloquio Jurídico Europeo).

Pucinelli, Óscar (1999): El Habeas Data en Indoiberoamérica (Santa fe de Bogotá, Temis). 
Purtova, Nadezhda (2009): "Property Rights in Personal Data: Learning from the American Discourse", en Computer Law and Security Review (Vol. 5, No. 6).

Purtova, Nadezhda (2009): “The illusion of personal data as no one's property", en Law, Innovation and Technology (Vol. 7, No. 1), pp. 83-111.

QuezadA, Flavio (2012): "La protección de datos personales en la jurisprudencia del Tribunal Constitucional de Chile”. Revista Chilena de Derecho y Tecnología (Vol. 1. No. 1).

Rajevic, Enrique (2011): "Protección de datos y transparencia en la administración pública chilena: Inevitable y deseable ponderación”, en Arrieta, Raúl (coord.), Reflexiones sobre el Uso y Abuso de los Datos Personales en Chile (Santiago, Expansiva).

Reusser, Carlos (2018): Derecho al olvido. La protección de datos personales como límite a las libertades informativas (Santiago, DER ediciones).

Salas, Carolina (2014): "Hábeas Data”, en Silva, María Pía \& Henríquez, Miriam (coords.), Acciones Protectoras de Derechos Fundamentales (Santiago, Thomson Reuters).

SchwaBe, Jürgen (2009): Jurisprudencia del Tribunal Constitucional Federal Alemán (México, DF, Konrad Adenuaer Stiftung).

Schwartz, Paul M. (2004): "Property, Privacy, and Personal Data", en Harvard Law Review (Vol. 117, No. 7), pp. 2056-2128.

Solove, Daniel J. (2004): The digital person. Technology and privacy in the information age (New York, New York University Press).

Solove, Daniel J. (2008); Understanding privacy (Cambridge, Mass., Harvard University Press).

Solove, Daniel J. \& Schwartz, Paul M. (2017): Privacy Law Fundamentals 2017 (Portsmouth, IAPP).

Solove, Daniel J. \& Schwartz, Paul M. (2018): Information Privacy Law (New York, Wolters Kluwer, $6^{\mathrm{a}}$ ed.).

Tzanou, Maria (2017): The Fundamental Right to Data Protection. Normative Value in the Context of Counter-Terrorism Surveillance (Oxford, Hart Pub.).

Velásquez, Juan \& Donoso, Lorena (2013), Tratamiento de Datos Personales en Internet. Los desafíos jurídicos en la era digital (Santiago, LegalPublishing Thomson Reuters).

Verdugo, Mario ET AL. (2002): Derecho Constitucional (Santiago, Edit. Jurídica de Chile), Tomo I, $2^{\text {a }}$ ed. 
Vial Claro, Felipe (2001). "La Ley No. 19.628 Sobre Protección de Datos de Carácter Persona. Una Visión General”, en WAHL, Jorge (ed.), Tratamiento de Datos Personales y Protección de la Vida Privada. Estudios sobre la Ley No. 19.628 Sobre Protección de Datos de Carácter Personal (Santiago, Chile. Ediciones Universidad de los Andes).

VIAL, Tomás (2012): "Los fallos de 2011 del Tribunal Constitucional sobre aplicación de la Ley de Transparencia a Televisión Nacional de Chile y a la Universidad de Chile", en Anuario de Derecho Público (Santiago, Ediciones UDP).

VICTOR, Jacob M. (2013): “The EU General Data Protection Regulation: Toward a Property Regime for Protecting Data Privacy”, en Yale Law Journal (Vol. 123), pp. 513-528.

Wacks, Raymond (2015): Privacy. A Very Short Introduction (Oxford, Oxford University Press).

Westin, Alan (1967): Privacy and Freedom (New York, IG Pub.).

Winegar, Angela G. \& Sunstein, Cass R. (2019): "How Much Is Data Privacy Worth? A Preliminary Investigation". [Fecha de consulta: 07.08.19] [Disponible en: https://ssrn.com/abstract=3413277].

\section{Normas jurídicas citadas}

Ley $\mathrm{N}^{\circ} 19.628$, sobre protección de la vida privada. Diario Oficial, 28 de ral de protección de datos), de 27 de abril de 2016.

\section{Jurisprudencia citada}

Sentencia del Tribunal Constitucional Federal Alemán, BVerfGE 27, 1 (1969).

Sentencia del Tribunal Constitucional Federal Alemán, BVerfGE 65, 1 (1983).

Sentencia del Tribunal Constitucional Español No. 292/200o.

Sentencia del Tribunal Constitucional de Chile, Roles $\mathrm{N}^{\circ} 1732-10$ y 180o-10, de 21 de junio de 2011. 